\title{
Can Hearing Aids Delay Time to Diagnosis of Dementia, Depression or Falls in Older Adults?
}

\author{
Elham Mahmoudi, $\mathrm{PhD}^{1,2}$ \\ Tanima Basu, $\mathrm{MS}^{2}$ \\ Kenneth Langa, MD, $\mathrm{PhD}^{2,4,5,6}$ \\ Michael M. McKee, MD, MPH ${ }^{1,2}$ \\ Phillip Zazove, $\mathrm{MD}^{3}$ \\ Neil Alexander, MD ${ }^{4,7}$ \\ Neil Kamdar, MA A $^{2,8,9,10}$
}

1. Assistant Professor, Department of Family Medicine, University of Michigan Medical School, Ann Arbor, MI

2. Institute for Healthcare Policy and Innovation, University of Michigan, Ann Arbor, MI

3. Professor, Department of Family Medicine, University of Michigan Medical School, Ann Arbor, MI

4. Professor, Department of Internal Medicine, University of Michigan Medical School, Ann Arbor, MI

5. Professor, Institute for Social Research, University of Michigan, Ann Arbor, MI

6. Professor, VA Center for Clinical Management Policy Research

7. Research Professor, Institute of Gerontology, University of Michigan, Ann Arbor, MI

8. Statistician Expert, Department of Obstetrics and Gynecology, University of Michigan Medical School, Ann Arbor, MI

9. Statistician Expert, Department of Surgery, University of Michigan Medical School, Ann Arbor, MI

10. Statistician Expert, Department of Emergency Medicine, University of Michigan Medical School, Ann Arbor, MI

Running Title: Hearing Aids and Delay in Age-related Conditions

Key Words: Hearing Loss; Hearing Aids; Aging Morbidities; Alzheimer’s; Dementia;

Depression; Anxiety; Alcohol Disorder; Drug Disorder; Fall; Optum

Abstract: $300 / 300$

Manuscript: 3,036/3,000

Corresponding Author:

Elham Mahmoudi, Ph.D., M.S.

University of Michigan

North Campus Research Complex, 2800 Plymouth Rd.

This is the author manuscript accepted for publication and has undergone full peer review but has not been through the copyediting, typesetting, pagination and proofreading process, which may lead to differences between this version and the Version of Record. Please cite this article as doi: $10.1111 /$ jgs.16109

This article is protected by copyright. All rights reserved. 
Building 14, Room G234

Ann Arbor, MI 48109

Email: Mahmoudi@med.umich.edu

Phone: 734-647-8136

This article is protected by copyright. All rights reserved. 


\begin{abstract}
Objective: To examine the association between hearing aids (HAs) and time to diagnosis of Alzheimer's or dementia, anxiety or depression, and injurious falls among adults aged 66 and older within 3 years of hearing loss (HL) diagnosis.

Design: Retrospective cohort study.

Setting: We used 2008-2016 national longitudinal claims data (based on office-visit, inpatient, or outpatient healthcare encounters) from a large private payer. We used Kaplan Meier curves to examine unadjusted disease-free survival and crude and adjusted Cox regression models to examine associations between HAs and time to diagnosis of 3 age-related/HL-associated conditions within 3 years of HL diagnosis. All models were adjusted for age, sex, race/ethnicity, Census Divisions, and prior diagnosis of cardiovascular conditions, hypertension, hypercholesterolemia, obesity, and diabetes.
\end{abstract}

Participants: 114,862 adults aged 66 and older diagnosed with HL.

Measurement: Diagnosis of (1) Alzheimer’s disease or dementia; (2) depression or anxiety; and (3) injurious falls.

Intervention: Use of HAs.

Results: Large gender and racial/ethnic differences exist in HA use. Approximately $11.3 \%$ of women vs. $13.3 \%$ of men used HAs (95\% CI Difference: $-0.024,-0.016)$. About $13.6 \%$ of Whites (95\% CI: $0.13,0.14)$ vs. 9.8\% of Blacks (95\% CI: $0.09,0.11)$ and 6.5\% of Hispanics (95\% CI: 0.06, 0.07) used HAs. The risk-adjusted hazard ratios of being diagnosed with

This article is protected by copyright. All rights reserved. 
Alzheimer’s disease/dementia, anxiety/depression, and injurious falls within 3 years after HL diagnosis, for those who used HAs vs. those who did not, were 0.82 (95\% CI: 0.76-0.89), 0.89 (95\% CI: 0.86-0.93), and 0.87 (95\% CI: 0.80-0.95), respectively.

Conclusions: Use of HAs is associated with delayed diagnosis of Alzheimer's, dementia, depression, anxiety, and injurious falls among older adults with HL. Although we have shown an association between use of HA and reduced risk of physical and mental decline, randomized trials are needed to determine whether, and to what extent, the relationship is causal.

This article is protected by copyright. All rights reserved. 


\section{Introduction}

More than 27 million Americans 65 years and older live with hearing loss (HL). ${ }^{1}$

Prevalence of HL is estimated to grow due to our growing geriatric population. ${ }^{2}$ Prior literature indicates strong associations between HL and adverse conditions such as social isolation, depression, ${ }^{3,4}$ cognitive decline, ${ }^{5-7}$ injuries associated with falls, ${ }^{8}$ and reduced quality of life..$^{9,10}$ Despite these findings, use of hearing aids (HAs) as a potential treatment intervention for those with HL remains low. ${ }^{1}$ This has been attributed to multiple factors, including lack of perceived need, limited apparent benefit, ${ }^{1}$ uncomfortable fit, a complex system of hearing care with multiple points of contact, ${ }^{11}$ stigma, $^{12}$ and cost $^{13}$ (exacerbated by no or low insurance coverage in the U.S.). ${ }^{14}$

There is a paucity of research on the impact of HAs on medical outcomes. Further, the results of these studies are often inconsistent. For example, Dawes et al. found no significant differences in cognitive and mental health outcomes between HA users and non-users. ${ }^{15}$ A crosssectional analysis of 164,770 adults ages 40 to 69 with HL in the UK found better cognitive function among those who used HAs compared with those who did not. ${ }^{16}$ A recent review of the literature ${ }^{17}$ by Hubbard et al. showed that hearing interventions have been successful in slowing the progression of cognitive decline among aging adults without dementia. ${ }^{18-20}$ Despite contradictory findings and lack of literature studying this population, evidence-based research on hearing interventions among older adults with $\mathrm{HL}$ is gaining momentum. ${ }^{17}$ More longitudinal research on this topic is warranted. 
Although routine HL examinations and HA-related expenditures are not covered by Medicare fee-for-service, many managed care plans cover a portion of HA costs. Thus, we used nationwide claims data from a private managed care payer to examine the association between HA use and time to diagnosis of 3 common conditions among adults 66 years and older who were diagnosed with HL: (1) Alzheimer’s disease (AD) or dementia;,21 (2) depression or anxiety; ${ }^{22,23}$ and (3) injuries related to falls. ${ }^{8,24}$ We hypothesized that HAs are associated with a delay in diagnosis of the above age-related conditions.

\section{Methods}

\section{Data Source}

This retrospective cohort study of adults with HL diagnoses defined in any patient care setting used a national, private insurance claims database, Clinformatics ${ }^{\circledR}$ DataMart Database (OptumInsight, Eden Prairie, MN). This de-identified claims database captures all emergency department (ED), outpatient, and inpatient encounters of over 79 million adults and children who were commercially insured by a single, large U.S. private payer and who had both medical and pharmacy coverage throughout their enrollment. The study was deemed exempt by the Institutional Review Board (IRB) at the researchers' institution.

\section{Patient Selection}

The study period covered 2008 to 2016. Using all private payer claims data between January 1, 2008 and December 31, 2013, adults age >= 66 years with ICD-9-CM, International Classification of Diseases, $9^{\text {th }}$ Revision, Clinical Modification, diagnosis codes for HL were 
identified (Table S1). Diagnosis of HL is usually done by an audiologist. To identify patients with incident HL, those with HL diagnoses or HA procedure codes within one year prior to the incident HL were excluded (Table S2). Additional exclusion criteria included (1) fewer than 12 months of continuous enrollment prior to index HL diagnosis, (2) pre-existing diagnosis of dementia, $\mathrm{AD}$, anxiety, depression, and a fall leading to injury within 12 months prior to the index HL diagnosis (Table S3); ${ }^{25,26}$ and (3) not having at least 3 years of continuous enrollment after the index HL. Figure 1 depicts the final sample size.

Dependent and Explanatory Variables

Outcomes included being diagnosed with AD or dementia, depression or anxiety, and injurious fall, as determined by ICD-9 and ICD-10 codes. The difference in days for the time to the outcome was calculated by identifying the first claim service date with any diagnosis of the three outcome conditions in the 3-year period following the index HL. Baseline demographic characteristics included age, sex, race and ethnicity, and U.S. Census Division (New England, Mid Atlantic, East North Central, West North Central, South Atlantic, East South Central, West South Central, Mountain, Pacific) at the time of HL diagnosis. Comorbidities for risk adjustment included hypertension (non-gestational), diabetes (non-gestational), obesity, cardiovascular conditions, and hypercholesterolemia in the 12 months prior to HL diagnosis. These conditions were chosen because of their higher prevalence among people with HL. ${ }^{27}$ Statistical Analysis

This article is protected by copyright. All rights reserved. 
Bivariate analyses of baseline demographic characteristics and comorbid conditions at the time of HL diagnosis were conducted for HA users and non-users. For categorical variables, bivariate analysis was conducted using Chi-Square testing, and 95\% confidence intervals for differences in proportions were calculated. For continuous variables, means and standard deviations were calculated and their distributions were examined to ensure robustness of parametric T-tests.

To examine disease-free survival of HA users versus non-users, Kaplan-Meier productlimit survival curves were constructed for each outcome. Log-Rank tests were applied to examine the proportional hazards assumption and to test for differences in survival curves. Patients were right censored if they did not experience the outcome in the 3-year follow-up period. Cox proportional hazards regression models were developed to calculate unadjusted and risk adjusted hazard ratios to measure the effect of HA use on each outcome.

Additionally, state-level variation in incidence rates of outcomes was assessed by calculating the state-specific unadjusted rates over the entire timeframe of 2008-2016. All states were ranked and split into tertiles based on their unadjusted incident rates of HA use and the three outcomes. To examine the hypothesized effect of state-specific HA utilization on each outcome, a Pearson's correlation coefficient was calculated. To assess geographic variation, state-level heat maps were developed and divided into tertiles. The strength of the association of HA utilization and outcomes was measured via Pearson's correlation coefficients (Figure S1 and 
Table S4). All analyses were conducted using SAS 9.4 (SAS Institute Inc., Cary, NC, USA).

Statistical testing was two-tailed, with a 0.05 significance level.

Sensitivity Analysis

The effect of selection bias was examined by performing propensity score matching using multivariable logistic regression adjusting for the following observable confounders: age, sex, U.S. Census Division, and clinically relevant medical conditions. We used a caliper matching algorithm is caliper size of 0.001 with a 1:1 ratio of hearing aid users (cases) to controls (hearing aid non-users) without replacement. After propensity score matching, Cox regression models were fit with HA as the main effect to estimate hazard ratios for each outcome. The results did not appreciably change (Table S5). Therefore, main results are presented without propensity matching.

\section{Results}

In a sample of 114,862 adults aged 66 or older diagnosed with HL, 14,109 (12.3\%) used HAs (Table 1). The mean (SD) age was 75.8 (5.8) years, with no significant difference between those with and without HAs. Approximately $11.3 \%$ of female vs. $13.3 \%$ of males (diff: $2.0 \%$; 95\% CI, $-0.0237,-0.0161$ ) had HAs, along with 13.6\% of whites vs. 9.8\% of Blacks (diff: 3.8\%; 95\% CI: $0.0300,0.0451)$ and 6.5\% of Hispanics (diff: 7.1\%; 95\% CI: 0.0653, 0.0760) (p < 0.0001 for all). Among the 9 U.S. Census Divisions, the highest level of HA use (36.9\%) was in the West North Central Division (Iowa, Kansas, Minnesota, Missouri, Nebraska, North Dakota and South Dakota). The lowest (5.9\%) was in the Mountain Division (Idaho, Montana, 
Wyoming, Nevada, Utah, Colorado, Arizona, New Mexico) $(\mathrm{p}<0.0001)$. On average, the prevalence of hypertension (24.4\% vs. 21.6\%; $\mathrm{p}<0.0001)$, hypercholesterolemia (47.9\% vs 44.4\%; $\mathrm{p}<0.0001)$, and diabetes (17.9\% vs. $15.5 \%(\mathrm{p}<0.0001)$ were higher among patients without HAs compared with those with HAs.

Figure 2 shows the unadjusted hazard ratios for diagnosis of each outcome within a 3year period. For all 3 outcomes, HA users had lower hazard ratios than non-HA users: AD or dementia (0.83; 95\% CI:0.77-0.89), depression or anxiety (0.86; 95\% CI: 0.83-0.90), and injurious fall (0.87; 95\% CI:0.80-0.93).

Kaplan-Meier curves in Figure 3 also indicate delays in diagnosis of the three outcomes among adults with HL who used HAs compared with those who did not. Within 3 years of HL diagnosis, a higher percentage remained free of a diagnosis of AD or dementia (96.6\% vs. 96.1\%), depression or anxiety (83.5\% vs. $81.6 \%)$, or a fall (94.9\% vs. $94.2 \%)$.

The risk adjusted hazard ratio for developing $\mathrm{AD}$ or dementia within 3 years of being diagnosed with HL was lower by 0.82 (95\% CI: 0.76-0.89) among those who used HAs than those who did not. For depression or anxiety, it was lower by 0.89 (95\% CI: 0.86-0.93). For injurious falls, it was lower by 0.87 (95\% CI: 0.80-0.95) (Table 2). The estimated models and corresponding hazard ratios are reported in supplemental materials (Tables S6-S9).

Correlations between HA use and the 3 outcomes were also examined at the state level. The heat maps in Figures S1 depict substantial geographic clustering among the 52 states in incidence rates of HA use and the 3 outcomes. For example, the incidence of HA use in the 
majority of Pacific Division states (i.e. Oregon, Washington, California) was lower than in WestNorth-Central states (i.e. Minnesota, Iowa, Missouri). Conversely, the incidence of AD and dementia, and anxiety and depression were higher in Pacific states compared with West North Central states. State-level Pearson correlation coefficients did not indicate significant correlation between HA use and the 3 outcomes (Table S4).

\section{Discussion}

In a large national database of insurance claims, use of HAs among adults with HL was associated with a significantly lower risk of being diagnosed with AD or dementia, depression or anxiety, and injurious falls. We also found significant racial/ethnic and gender disparities in use of HAs.

By providing enhanced hearing input, HAs may facilitate greater social engagement, lower levels of effort to recognize sounds and speech, lower levels of depression or anxiety symptoms, higher levels of physical balance, and greater feelings of independence and selfefficacy. ${ }^{28-31}$ Believing in one's physical and cognitive ability to socially engage and accomplish a task or participate in social events has been shown to advance cognitive measurements. In contrast, isolation and depression are independently associated with $\mathrm{AD}$ and dementia-related illnesses. ${ }^{32,33}$ Despite evidence related to the positive association between HA use and improvement in quality of life and well-being, prior studies have reported conflicting results regarding the preventative role of HAs in age-related conditions. ${ }^{15,34-37}$

This article is protected by copyright. All rights reserved. 
The present findings support previous literature on substantial gender and racial/ethnic disparities in the use of HAs. ${ }^{12,34,38}$ The underlying factors behind these disparities have been discussed extensively. ${ }^{39,40}$ Our findings are unique because they underscore the importance of protective associations of HA with each of our conditions that are more common among females and minorities. For example prevalence of $\mathrm{AD}$ or dementia ${ }^{41,42}$ and anxiety or depression ${ }^{42,43}$ are substantially higher among females than males as well as among African Americans compared to Caucasians. It follows that reducing disparities in access and use of HAs is likely attributable to insurance coverage and affordability among these subpopulations. It is also conceivable that other salient factors, such as severity of hearing loss, frailty, socioeconomic status, lifestyle and behavior choices are associated with diagnosis of age-related conditions.

Mounting evidence indicates strong associations between HL and cognitive decline and increased risk of falls among older adults. ${ }^{5,15,44,45}$ Two main theories explain this association: (1) cascade theory and (2) common cause theory. ${ }^{46,47}$ The cascade theory hypothesizes that extended periods of uncorrected HL cause more isolation and less stimulation, which may lead to cognitive decline among older adults. ${ }^{47}$ The common cause theory hypothesizes that both HL and physical and cognitive decline are associated with aging changes in the nervous system, meaning that both are part of the normal aging process. ${ }^{48}$

Our findings corroborate existing literature asserting that use of HAs is associated with lower risk of being diagnosed with AD or dementia, anxiety or depression, and falls. ${ }^{49}$ Recent studies found hearing interventions to be protective against further cognitive decline among older 
adults with dementia. For example, Maharani et al. found reduced rates of decline in episodic memory scores among older adults with HL and dementia after they started using HAs. ${ }^{50}$ Prolonged sensory deprivation due to hearing or vision loss has been linked to social isolation, delirium, and cognitive decline. ${ }^{51}$ Our findings posit additional evidence that HL may be a modifiable risk factor (through HA intervention) for AD or dementia.

Additionally, HL has been linked with depression and anxiety. ${ }^{32}$ People at greater risk of isolation because of functional or sensory impairments are prone to experience depression. Our results suggest that HAs may delay diagnosis of depression and anxiety among individuals with HL. While improvement in one-to-one and group conversations in various social and healthcare settings is important, HA use also confers improvements in independently accomplishing tasks, work productivity, self-awareness, self-confidence, and self-advocacy.

Age-related HL is negatively associated with balance function and increases the risk of fall-related injuries. ${ }^{52,53}$ Plausibly, this could be explained by poorer spatial awareness or cognitive overload resulting from auditory deprivation among adults with HL. A decline in the ability to notice auditory cues may lead to lower awareness of one's surroundings and thus to higher incidence of falls. ${ }^{8}$

Currently, there is no standard estimate of incidence or prevalence for each of the outcomes in our study. Depending upon the data source, there can be vastly different prevalence and incidence estimates. For instance, the Health and Retirement Study linked to Medicare administrative claims data has shown that cognitive test results from survey data versus 
diagnoses from claims data can yield very different incidence for dementia. ${ }^{54}$ For example, among Whites, incidence of dementia based on cognitive tests from surveys was lower than that using diagnosis codes from claims (3.2\% versus $12.3 \%) .{ }^{54}$ In contrast, among Blacks, dementia incidence was higher using cognitive tests compared to that using diagnosis codes $(15.2 \%$ vs. $11.1 \%)^{54}$

Prior literature shows incidence for dementia, injurious falls, and depression in the general geriatric population is $12.2 \%,{ }^{54} 7.5 \%,{ }^{55}$ and $25.2 \%,{ }^{56}$ respectively. In support of previous literature, our findings indicate higher incidence of these conditions among hearing loss patients. From 2008-2016, we found incidence of dementia, injurious falls, and depression for hearing loss patients to be $13.9 \%, 12.7 \%$, and $35.6 \%$, respectively.

It is important to note that on average HAs cost between $\$ 2,000-\$ 7,000$ and are not covered (or are underinsured) by most health plans, which shifts the financial burden of HAs to patients. ${ }^{40}$ Today, more than 27 million older Americans live with HL, but only about $14 \%$ of them use HAs. ${ }^{1}$ While cost is a pertinent and plausible barrier to access to HAs, efforts have been made to improve access. The US PCAST ${ }^{57}$ report asserts that the HA prescription process should be made similar to that for eyeglasses and contact lenses. Furthermore, the Over-theCounter Hearing Aid Act ${ }^{58}$ enables availability of hearing aids over the counter without a prescription. Although HAs are expensive, the medical costs of many conditions that could be prevented or delayed by using HAs are substantially more expensive. For example, in 2017, the annual incidence rate of AD among Americans aged 65 years or older was 480,000 patients; by

This article is protected by copyright. All rights reserved. 
2050, this is expected to rise to approximately 1 million patients. ${ }^{41}$ Average annual direct healthcare payments (in 2016 dollars) are $\$ 46,000$ for each patient with $\mathrm{AD}$ alone (approximately \$34,000 more than direct healthcare spending for those without AD). ${ }^{41}$ Any delay in diagnosis of $\mathrm{AD}$ or dementia could not only lead to large cost savings, but also improve the health and well-being of older adults.

\section{Limitations}

Our study has a number of potential limitations. First, inherent limitations of using claims data include a lack of information about patients’ socioeconomic status, lifestyle choices, educational attainment, and other salient factors. While appropriate use of HAs might delay the diagnosis of age-related conditions, HA users could have different lifestyle choices and resources available to them that could also contribute to a delayed diagnosis of these conditions. Second, since we use claims and diagnostic codes to define $\mathrm{HL}$, we may be unable to identify all patients with HL. HL patients without official diagnoses may not be included; others may have been incorrectly included as new patients if their diagnosis preceded the 12-month look-back period. Furthermore, claims data do not include direct audiometric measurements of HL. We were able to identify those who were diagnosed with HL but could not determine HL severity. We assumed that the majority of adults aged 66 and older who were diagnosed with HL had moderate to severe HL, and thus were in need of HAs. Third, we did not have any way to measure frequency and duration of HA use, if any, among individuals who purchased HAs. Often HAs are not fitted

properly, and people do not use their HAs consistently. ${ }^{14}$ There are also cultural taboos among 
many subpopulations such as minorities and females regarding the use of HAs. Individuals with HL may purchase HAs on the advice of physicians or family members, but rarely use them. Fourth, analysis of falls is complex. Using claims data, we controlled for no history of fallrelated injuries during the 12-month period before index hearing-loss diagnosis but were not able to control for other fall-related factors. Finally, our data came from a private insurance database which might introduce biases into our findings associated with the health status and higher functioning of Medicare Managed Care patients. Furthermore, state-level market penetration from a single large private payer varies; therefore, in the absence of sampling weights, national prevalence is not estimable at this time

The study’s strengths include having a large sample size due to using claims data, which contain large sample sizes and longitudinal follow up of health services and provide a broad clinical perspective on health outcomes over time. Since HAs are not covered by Medicare feefor-service, this covers an important segment of the population that likely has at least some coverage for HAs. Therefore, we examined a reasonably exhaustive snapshot of their service utilization.

To ensure the absence of prior diagnosis of our outcomes, a one-year clean period was used as a sufficient amount of time to ensure no pre-existing diagnoses. This enabled us to measure the association between HAs and time-to-diagnosis of 3 conditions within 3 years of HL diagnosis, controlling for confounding demographics and comorbidities.

\section{Conclusion}

This article is protected by copyright. All rights reserved. 
Use of HAs among adults with HL was associated with delay or prevention of 3 common and important age-related conditions: AD or dementia, depression or anxiety, and fall-related injuries. Timely diagnosis of HL and early use of HAs may delay the diagnosis of cognitive decline and reduce the risk of injurious falls.

This article is protected by copyright. All rights reserved. 


\section{References}

1. Chien W, Lin FR. Prevalence of hearing aid use among older adults in the United States. Archives of internal medicine. 2012;172(3):292-293.

2. Lin FR, Niparko JK, Ferrucci L. Hearing loss prevalence in the United States. Archives of internal medicine. 2011;171(20):1851-1853.

3. Mener DJ, Betz J, Genther DJ, Chen D, Lin FR. Hearing loss and depression in older adults. Journal of the American Geriatrics Society. 2013;61(9):1627-1629.

4. Dawes P, Cruickshanks KJ, Moore DR, et al. Cigarette smoking, passive smoking, alcohol consumption, and hearing loss. Journal of the Association for Research in Otolaryngology. 2014;15(4):663-674.

5. Lin FR. Hearing loss and cognition among older adults in the United States. Journals of Gerontology Series A: Biomedical Sciences and Medical Sciences. 2011;66(10):11311136.

6. Lin FR, Ferrucci L, Metter EJ, An Y, Zonderman AB, Resnick SM. Hearing loss and cognition in the Baltimore Longitudinal Study of Aging. Neuropsychology. 2011;25(6):763.

7. Lin FR, Metter EJ, O’brien RJ, Resnick SM, Zonderman AB, Ferrucci L. Hearing loss and incident dementia. Archives of neurology. 2011;68(2):214-220.

8. Lin FR, Ferrucci L. Hearing loss and falls among older adults in the United States. Archives of internal medicine. 2012;172(4):369-371.

9. Cherko M, Hickson L, Bhutta M. Auditory deprivation and health in the elderly. Maturitas. 2016;88:52-57.

10. Dalton DS, Cruickshanks KJ, Klein BE, Klein R, Wiley TL, Nondahl DM. The impact of hearing loss on quality of life in older adults. The Gerontologist. 2003;43(5):661-668.

11. Donahue A, Dubno JR, Beck L. Accessible and affordable hearing health care for adults with mild to moderate hearing loss. Ear and hearing. 2010;31(1):2.

12. McKee MM, Choi H, Wilson S, DeJonckheere MJ, Zazove P, Levy H. Determinants of Hearing Aid Use Among Older Americans With Hearing Loss. The Gerontologist. 2018.

13. Mahmoudi E, Zazove P, Meade M, McKee MM. Association between hearing aid use and health care use and cost among older adults with hearing loss. JAMA Otolaryngology-Head \& Neck Surgery. 2018.

14. McCormack A, Fortnum H. Why do people fitted with hearing aids not wear them? International journal of audiology 2013;52:360-8.

15. Dawes P, Cruickshanks KJ, Fischer ME, Klein BE, Klein R, Nondahl DM. Hearing-aid use and long-term health outcomes: Hearing handicap, mental health, social engagement, cognitive function, physical health, and mortality. International journal of audiology. 2015;54(11):838-844.

16. Dawes P, Emsley R, Cruickshanks KJ, et al. Hearing loss and cognition: the role of hearing AIDS, social isolation and depression. PloS one. 2015;10(3):e0119616. 
17. Hubbard HI, Mamo SK, Hopper T. Dementia and Hearing Loss: Interrelationships and Treatment Considerations. Seminars in speech and language. 2018;39(03):197-210.

18. Deal JA, Albert MS, Arnold M, et al. A randomized feasibility pilot trial of hearing treatment for reducing cognitive decline: results from the Aging and Cognitive Health Evaluation in Elders Pilot Study. Alzheimer's Dementia: Translational Research Clinical interventions in aging. 2017;3(3):410-415.

19. Taljaard DS, Olaithe M, Brennan-Jones CG, Eikelboom RH, Bucks RS. The relationship between hearing impairment and cognitive function: a meta-analysis in adults. Clinical Otolaryngology. 2016;41(6):718-729.

20. Miller G, Miller C, Marrone N, Howe C, Fain M, Jacob A. The impact of cochlear implantation on cognition in older adults: a systematic review of clinical evidence. $B M C$ geriatrics. 2015;15(1):16.

21. Uhlmann RF, Larson EB, Rees TS, Koepsell TD, Duckert LG. Relationship of hearing impairment to dementia and cognitive dysfunction in older adults. JAMA. 1989;261(13):1916-1919.

22. Mener DJ, Betz J, Genther DJ, Chen D, Lin FR. Hearing loss and depression in older adults. Journal of the American Geriatrics Society 2013;61:1627-9.

23. Kvam MH, Loeb M, Tambs K. Mental health in deaf adults: symptoms of anxiety and depression among hearing and deaf individuals. The Journal of deaf studies and deaf education. 2007;12(1):1-7.

24. Jiam NTL, Li C, Agrawal Y. Hearing loss and falls: A systematic review and metaanalysis. The Laryngoscope. 2016;126(11):2587-2596.

25. Swenson CW, Kamdar NS, Seiler K, Morgan DM, Lin P, As-Sanie S. Definition development and prevalence of new persistent opioid use following hysterectomy. Am $J$ Obstet Gynecol. 2018;219(5):486. e481-486. e487.

26. Peterson MD, Kamdar N, Hurvitz EA. Age-related trends in cardiometabolic disease among adults with cerebral palsy. Developmental Medicine Child Neurology. 2019;61(4):484-489.

27. Besser J, Stropahl M, Urry E, Launer S. Comorbidities of hearing loss and the implications of multimorbidity for audiological care. Hearing Research. 2018.

28. Chou R, Dana T, Bougatsos C, Fleming C, Beil T. Screening adults aged 50 years or older for hearing loss: a review of the evidence for the US preventive services task force. Annals of internal medicine. 2011;154(5):347.

29. Ciorba A, Bianchini C, Pelucchi S, Pastore A. The impact of hearing loss on the quality of life of elderly adults. Clinical interventions in aging. 2012;7:159.

30. Joore MA, Potjewijd J, Timmerman A, Anteunis L. Response shift in the measurement of quality of life in hearing impaired adults after hearing aid fitting. Quality of Life Research. 2002;11(4):299-307.

31. Mulrow CD, Tuley MR, Aguilar C. Sustained benefits of hearing aids. Journal of Speech, Language, and Hearing Research. 1992;35(6):1402-1405. 
32. McKee MM, Stransky ML, Reichard A. Hearing loss and associated medical conditions among individuals 65 years and older. Disability and health journal. 2017.

33. Pacala JT, Yueh B. Hearing deficits in the older patient:“I didn't notice anything”. JAMA. 2012;307(11):1185-1194.

34. Bainbridge KE, Ramachandran V. Hearing aid use among older United States adults: The National Health and Nutrition Examination Survey, 2005-2006 and 2009-2010. Ear and hearing 2014;35:289.

35. Agrawal Y, Platz EA, Niparko JK. Prevalence of hearing loss and differences by demographic characteristics among US adults: data from the National Health and Nutrition Examination Survey, 1999-2004. Archives of internal medicine. 2008;168(14):1522-1530.

36. Chisolm TH, Johnson CE, Danhauer JL, et al. A systematic review of health-related quality of life and hearing aids: final report of the American Academy of Audiology Task Force on the Health-Related Quality of Life Benefits of Amplification in Adults. Journal of the American Academy of Audiology. 2007;18(2):151-183.

37. Mamo SK, Reed NS, Price C, et al. Hearing Loss Treatment in Older Adults With Cognitive Impairment: A Systematic Review. Journal of Speech, Language, and Hearing Research:1-15.

38. Nieman CL, Marrone N, Szanton SL, Thorpe Jr RJ, Lin FR. Racial/ethnic and socioeconomic disparities in hearing health care among older Americans. Aging Health 2016;28:68-94.

39. Wallhagen MI. The stigma of hearing loss. The Gerontologist 2009;50:66-75.

40. Mahmoudi E, Zazove P, Meade M, McKee MM. Association between hearing aid use and health care use and cost among older adults with hearing loss. JAMA Otolaryngology-Head \& Neck Surgery 2018.

41. Association As. 2017 Alzheimer's disease facts and figures. Alzheimer's \& Dementia. 2017;13(4):325-373.

42. Kessler RC. Epidemiology of women and depression. Journal of affective disorders 2003;74:5-13.

43. Williams DR, Gonzalez HM, Neighbors H, et al. Prevalence and distribution of major depressive disorder in African Americans, Caribbean blacks, and non-Hispanic whites: results from the National Survey of American Life. Archives of general psychiatry 2007;64:305-15.

44. Lin FR, Yaffe K, Xia J, et al. Hearing loss and cognitive decline in older adults. JAMA internal medicine. 2013;173(4):293-299.

45. Cherko M, Hickson L, Bhutta M. Auditory deprivation and health in the elderly. Maturitas 2016;88:52-7.

46. Lindenberger U, Ghisletta P. Cognitive and sensory declines in old age: gauging the evidence for a common cause. Psychology and aging 2009;24:1.

This article is protected by copyright. All rights reserved. 
47. Masten AS, Cicchetti D. Developmental cascades. Development psychopathology 2010;22:491-5.

48. Seidman MD, Ahmad N, Bai U. Molecular mechanisms of age-related hearing loss. Ageing research reviews 2002;1:331-43.

49. Chen DS, Betz J, Yaffe K, et al. Association of hearing impairment with declines in physical functioning and the risk of disability in older adults. Journals of Gerontology Series A: Biomedical Sciences Medical Sciences. 2014;70(5):654-661.

50. Maharani A, Dawes P, Nazroo J, et al. Longitudinal Relationship Between Hearing Aid Use and Cognitive Function in Older Americans. Journal of the American Geriatrics Society 2018.

51. Uchida Y, Sugiura S, Nishita Y, Saji N, Sone M, Ueda H. Age-related hearing loss and cognitive decline-The potential mechanisms linking the two. Auris Nasus Larynx 2018.

52. Tinetti ME, Speechley M, Ginter SF. Risk factors for falls among elderly persons living in the community. New England journal of medicine 1988;319:1701-7.

53. Crews JE, Campbell VA. Vision impairment and hearing loss among communitydwelling older Americans: implications for health and functioning. American journal of public health 2004;94:823-9.

54. Chen Y, Tysinger B, Crimmins E, Zissimopoulos JM. Analysis of dementia in the US population using Medicare claims: Insights from linked survey and administrative claims data. Alzheimer's Dementia: Translational Research Clinical interventions in aging 2019;5:197-207.

55 Shumway-Cook A, Ciol MA, Hoffman J, Dudgeon BJ, Yorkston K, Chan L. Falls in the Medicare population: incidence, associated factors, and impact on health care. Physical Therapy 2009;89:324-32.

56. Centers for Medicare and Medicaid Services. Physical and Mental Health Condition Prevalence and Comorbidity among Fee-for-Service Medicare- Medicaid Enrollees. 2014. https://www.cms.gov/Medicare-Medicaid-Coordination/Medicare-and-MedicaidCoordination/Medicare-Medicaid-CoordinationOffice/Downloads/Dual_Condition_Prevalence_Comorbidity_2014.pdf. Accessed 7/1/2019.

57. Cassel C, Penhoet E. PCAST Recommends Changes to Promote Innovation in Hearing Technologies. 2015; https://obamawhitehouse.archives.gov/blog/2015/10/26/\%E2\%80\%8Bpcastrecommends-changes-promote-innovation-hearing-technologies. Accessed 5/10/19.

58. The Hearing Review. US Senate Passes OTC Hearing Aid Act as Part of FDA Reauthorization Act of 2017. http://www.hearingreview.com/2017/08/us-senate-passesotc-hearing-aid-act-part-fda-reauthorization-act-2017-ada-announces/. Accessed 11/15/18.

This article is protected by copyright. All rights reserved. 


\section{Figure Legends:}

\section{Figure 1. Schematic Flow Diagram of the Sample Size}

Note: The study period covered 2008 to 2016. We identified adults age $>=66$ years of age with ICD-9-CM, International Classification of Diseases, $9^{\text {th }}$ Revision, Clinical Modification, diagnosis codes for hearing loss between January 1, 2008 and December 31, 2013.

Figure 2. Unadjusted Hazard Ratios for Developing Age-Related Conditions Among Adults with Hearing Loss Who Used Hearing Aids Compared with Those Who Did Not Note: Unadjusted hazard ratios and 95\% confidence intervals were determined using Cox proportional hazards regression models with hearing aid use as the covariate.

Figure 3. Kaplan-Meier Curves: Disease-free Time in Days to the Diagnosis of Three AgeRelated Conditions

Notes:

(1) All adults in the cohort had no diagnosis of Alzheimer's or dementia, anxiety or depression, or falls on a claim for one year prior to the index diagnosis of hearing loss. (2) All log rank tests were significant at the 0.05 level.

This article is protected by copyright. All rights reserved. 


\section{Supplementary Tables}

Table S1. ICD-9 and ICD-10 Diagnosis Codes for Hearing Loss

Table S2. Table S2. Procedure Codes for Hearing Aids

Table S3. ICD-9 and ICD-10 Diagnosis Codes for Alzheimer's and Dementia, Anxiety and Depression, Alcohol and Drug Disorders, and Fall

Table S4. Summary Statistics of the State-specific Proportions of the Outcomes of Interest Table S5. Propensity Matched Adjusted Hazard Ratios for Developing Aging-related Morbidities Among Patients with Hearing Loss Who Used Hearing Aids Compared with Those Without Hearing Aids*

Table S6. Cox Regression Results for Alzheimer's Disease or Dementia

Table S7. Cox Regression Results for Anxiety or Depression

Table S8. Cox Regression Results for Alcohol or Drug Disorders

\section{Supplementary Figures}

Figure S1. Heat Maps of Incidence Rates of Hearing Aid Use, Alzheimer's disease and/or Dementia, Anxiety and/or Depression, and Injurious Fall Within 52 States

This article is protected by copyright. All rights reserved. 
Table 1. Descriptive Characteristics of People 66 Years or Older with Hearing Loss with and Without Hearing Aids*

\begin{tabular}{|c|c|c|c|c|}
\hline & Total & $\begin{array}{c}\text { Without Hearing } \\
\text { Aids }\end{array}$ & $\begin{array}{l}\text { With Hearing } \\
\text { Aids }\end{array}$ & P Value* \\
\hline Variables & $\mathrm{N}=114,862$ & $\mathrm{~N}=100,753$ & $\mathrm{~N}=14,109$ & \\
\hline Age: & & & & $<0.0001$ \\
\hline $66-70$ & $28,685(25.0 \%)$ & 25,248 (88.0\%) & 3,437 (12.0\%) & \\
\hline $71-75$ & $27,126(23.6 \%)$ & 23897 (88.1\%) & 3229 (11.9\%) & \\
\hline $76-80$ & $24,553(21.4 \%)$ & 21615 (88.0\%) & $2938(12.0 \%)$ & \\
\hline $80+$ & $34,498(30.0 \%)$ & 29993 (86.9\%) & 4505 (13.1\%) & \\
\hline Gender: & & & & $<0.0001$ \\
\hline Female & 57885 (50.4\%) & $51338(88.7 \%)$ & 6547 (11.3\%) & \\
\hline Male & $56958(49.6 \%)$ & 49397 (86.7\%) & 7561 (13.3\%) & \\
\hline Unknown & $19(0.02 \%)$ & $18(94.7 \%)$ & $1(5.0 \%)$ & \\
\hline Race: & & & & $<0.0001$ \\
\hline White & 83,185 (72.4\%) & 71,887(86.4\%) & $11,298(13.6 \%)$ & \\
\hline Black & $6,688(5.8 \%)$ & $6,031(90.2 \%)$ & $657(9.8 \%)$ & \\
\hline Hispanic & $10,236(8.9 \%)$ & $9,570(93.5 \%)$ & 666 (6.5\%) & \\
\hline Asian & $3,741(3.3 \%)$ & 3,429 (91.6\%) & $312(8.3 \%)$ & \\
\hline Unknown/Missing & $11,012(10 \% \%)$ & $9,836(89.3 \%)$ & $1,176(10.7 \%)$ & \\
\hline Census Divisions+: & & & & $<0.0001$ \\
\hline New England & $4,843(4.2 \%)$ & $4,472(92.3 \%)$ & $371(7.7 \%)$ & \\
\hline Middle Atlantic & 6,803 (5.9\%) & $6,330(93.1 \%)$ & $473(6.9 \%)$ & \\
\hline East North Central & $10,011(8.7 \%)$ & 9,015 (90.1\%) & $996(9.9 \%)$ & \\
\hline West North Central & $15,810(13.8 \%)$ & $9,980(63.1 \%)$ & $5,830(36.9 \%)$ & \\
\hline South Atlantic & $20,718(18.0 \%)$ & $18,474(89.2 \%)$ & $2,244(10.8 \%)$ & \\
\hline East South Central & $2,650(2.3 \%)$ & $2,498(94.3 \%)$ & $152(5.7 \%)$ & \\
\hline West South Central & $11,512(10.0 \%)$ & 10,633 (92.4\%) & $879(7.6 \%)$ & \\
\hline Mountain & $14,590(12.7 \%)$ & 13,734 (94.1\%) & $856(5.9 \%)$ & \\
\hline Pacific & $26,236(22.8 \%)$ & 24,046 (91.7\%) & $2,190(8.3 \%)$ & \\
\hline Unknown or Puerto Rico & $1,689(1.5 \%)$ & $1,571(93.0 \%)$ & $118(7.0 \%)$ & \\
\hline Chronic Conditions: & & & & $<0.0001$ \\
\hline Cardiovascular & $39,518(34.4 \%)$ & $34,690(34.4 \%)$ & $4,828(34.2 \%)$ & \\
\hline Hypertension (complicated) & $27,602(24.0 \%)$ & $24,558(24.4 \%)$ & $3,044(21.6 \%)$ & \\
\hline Hypercholesterolemia & $54,544(47.5 \%)$ & $48,284(47.9 \%)$ & $6,260(44.4 \%)$ & \\
\hline Obesity & $16,703(14.5 \%)$ & $14,714(14.6 \%)$ & $1,989(14.1 \%)$ & \\
\hline Diabetes (complicated) & $20,197(17.6 \%)$ & $18,016(17.9 \%)$ & $2,181(15.5 \%)$ & \\
\hline
\end{tabular}

*Significance testing for age was performed using a t-test, and Chi-Square tests at an alpha $=0.05$ were used for all categorical variables.

+ Census Division: New England(Maine, New Hampshire, Vermont, Massachusetts, Rhode Island, Connecticut); Middle Atlantic(New York, Pennsylvania, New Jersey); East North Central(Wisconsin, Michigan, Illinois, Indianan, Ohio); West North Central(North Dakota, South Dakota, Nebraska, Kansas, Minnesota, Iowa, Missouri); South Atlantic(Delaware, Maryland, District of Columbia, Virginia, West Virginia, North Carolina, South Carolina, Georgia, Florida); East South Central(Kentucky, Tennessee, Mississippi, Alabama); West South Central(Oklahoma, Texas, Arkansas, Louisiana); 
Mountain(Idaho, Montana, Wyoming, Nevada, Utah, Colorado, Arizona, New Mexico); Pacific(Alaska, Washington, Oregon, California, Hawaii). 
Table 2. Crude and Adjusted Hazard Ratios (HR) with 95\% Confidence Intervals for Diagnosis of Age-Related Conditions Among Older Adults with Hearing Loss Who Used Hearing Aids Compared to Those Without Hearing Aids****

\begin{tabular}{|c|c|c|c|c|}
\hline $\begin{array}{c}\text { Aging-Related } \\
\text { Morbidity }\end{array}$ & Crude HR & P-Value & Adjusted HR & P-Value \\
\hline $\begin{array}{c}\text { Alzheimer's or } \\
\text { Dementia }\end{array}$ & $0.826(0.765,0.891)$ & $<0.001$ & $0.824(0.761,0.893)$ & $<0.001$ \\
\hline & & & & \\
\hline $\begin{array}{c}\text { Anxiety or } \\
\text { Depression }\end{array}$ & $0.863(0.827,0.900)$ & $<0.001$ & $0.894(0.856,0.934)$ & $<0.001$ \\
\hline Falls & $0.865(0.801,0.934)$ & $<0.001$ & $0.871(0.804,0.945)$ & $<0.001$ \\
\hline
\end{tabular}

*Crude hazard ratios and 95\% confidence intervals were estimated with hearing aid use as the primary exposure variable.

**Adjusted hazard ratios and 95\% confidence intervals were calculated using Cox proportional hazards regression models for age, gender, U.S. Census Division, hypertension, diabetes, hypercholesterolemia, obesity, and cardiovascular conditions (see Tables S6-S9). 


\begin{tabular}{|c|c|c|}
\hline \multirow{2}{*}{\multicolumn{2}{|c|}{$\begin{array}{l}\text { Hearing loss patients in the CY } 2008 \text { to } 2013 \\
\qquad N=950,933\end{array}$}} & \multirow{3}{*}{$\begin{array}{l}\text { Excluded patients younger than } 66 \text { years of age } \\
\qquad N=573,587\end{array}$} \\
\hline & & \\
\hline \multirow{2}{*}{\multicolumn{2}{|c|}{$\begin{array}{l}\text { Hearing loss patients in the CY } 2008 \text { to } 2013 \text { age } 66 /+ \text { years } \\
\qquad N=377,346\end{array}$}} & \\
\hline & & \multirow{2}{*}{$\begin{array}{l}\text { Excluded patients with less than } 1 \text { year pre- } \\
\text { continuous enrollment } \\
\qquad \mathrm{N}=98,591\end{array}$} \\
\hline \multirow{2}{*}{\multicolumn{2}{|c|}{$\begin{array}{l}\text { Hearing loss patients in the CY } 2008 \text { to } 2013 \text { age } 66 /+ \text { years and } 1 \text { year } \\
\text { pre-continuous enrollment } \\
\qquad N=278,755\end{array}$}} & \\
\hline & & \multirow{3}{*}{$\begin{array}{l}\text { Excluded patients with less than } 3 \text { years post- } \\
\text { continuous enrollment } \\
\qquad N=116,122\end{array}$} \\
\hline & 4 & \\
\hline \multirow{2}{*}{\multicolumn{2}{|c|}{$\begin{array}{l}\text { Hearing loss patients in the CY } 2008 \text { to } 2013 \text { age } 66 /+ \text { years and } 1 \text { year } \\
\text { pre-continuous and } 3 \text { years post-continuous enrollment } \\
\qquad N=162,633\end{array}$}} & \\
\hline & & \multirow{3}{*}{$\begin{array}{l}\text { Excluded if patients had any of the given } \\
\text { outcomes: Alzheimer's or dementia, anxiety or } \\
\text { depression, and injurious fall prior to their } \\
\text { initial hearing loss diagnosis } \\
\qquad N=47,771\end{array}$} \\
\hline \multirow{2}{*}{\multicolumn{2}{|c|}{$\begin{array}{l}\text { Hearing loss patients in the CY } 2008 \text { to } 2013 \text { age } 66 /+ \text { years and } 1 \text { year } \\
\text { pre-continuous and } 3 \text { years post-continuous enrollment with exclusion } \\
\qquad N=114,862\end{array}$}} & \\
\hline & & \\
\hline $\begin{array}{l}\text { Hearing aids users } \\
\mathrm{N}=14,109(12.3 \%)\end{array}$ & $\begin{array}{l}\text { Hearing aid non-users } \\
\mathrm{N}=100,753(87.7 \%)\end{array}$ & \\
\hline
\end{tabular}

JGS_16109_Figure1.tiff

This article is protected by copyright. All rights reserved. 
Alzheimer's or Dementia

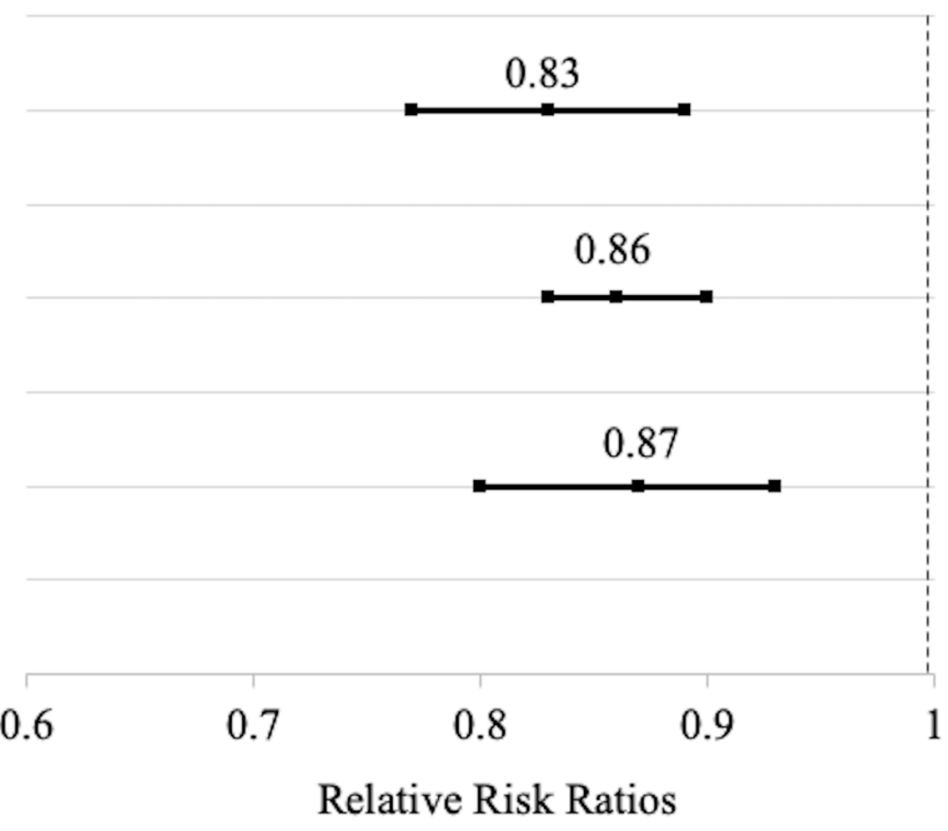

JGS_16109_Figure2.tiff

This article is protected by copyright. All rights reserved. 

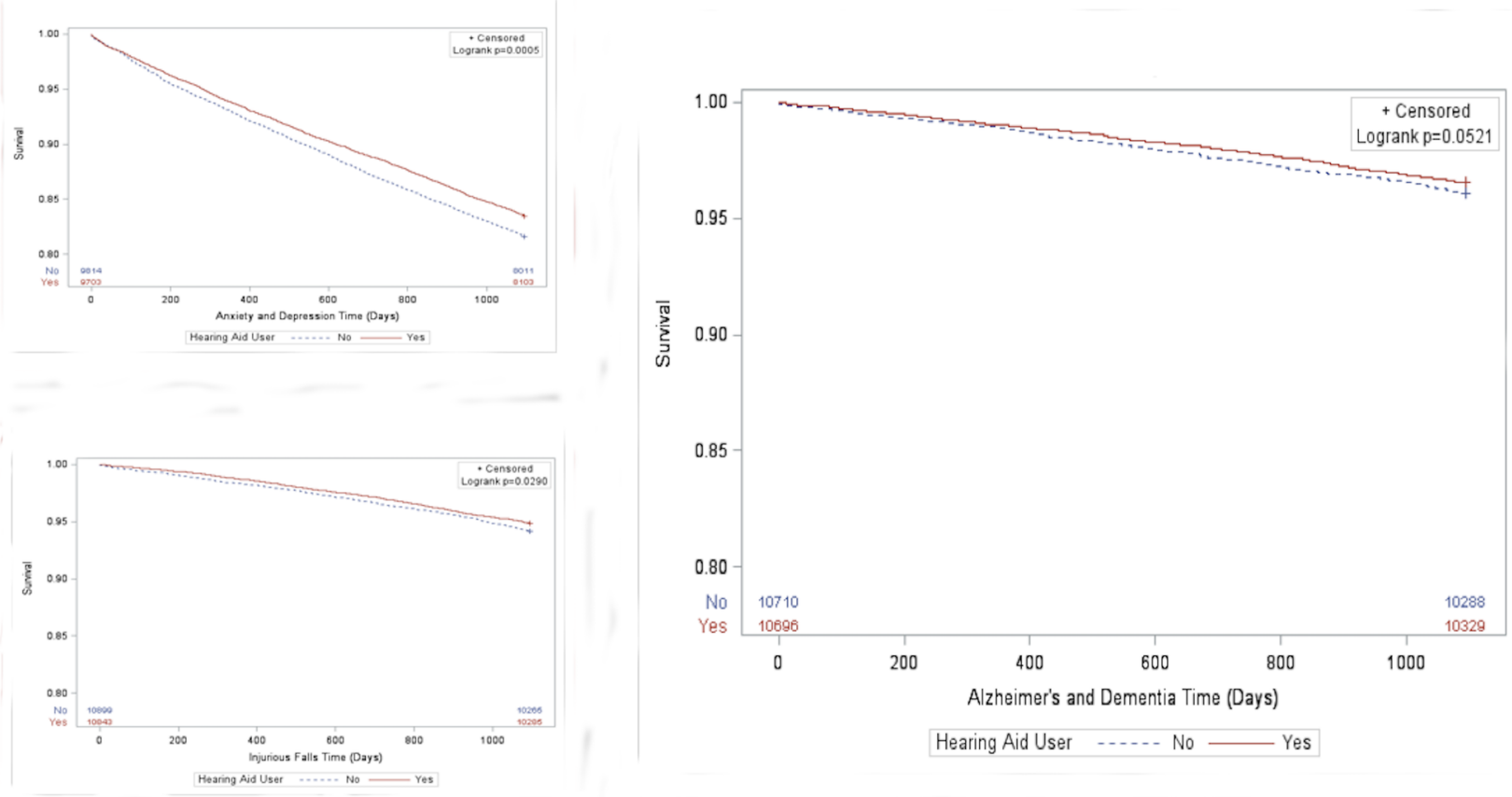

JGS_16109_Figure3.rev.tiff

This article is protected by copyright. All rights reserved. 


\section{Color Charge Form}

\section{Journal of the American Geriatrics Society}

\section{Upload this form to your submission OR return it to:}

Emily Hammond / JAGS Editorial Office

jags@jjeditorial.com

\section{Dear Author:}

If you have supplied color figures in your submission, the first color figure in print is free of cost. Any additional figures you wish to print in color will incur a fee of $\$ 500$ each. Please indicate how EACH of your figures should be handled in the table below.

INSTRUCTIONS:
For EVERY figure in your
paper, an $X$ should be provided
in the appropriate row.
Place an ' $X$ ' in column 1 for a
maximum of ONE figure.
Place an ' $X$ ' in column 2 if you
want to pay for additional color
printing. The total in this column
should be entered into the
Quantity field below.

should be entered into the

Quantity field below.

\begin{tabular}{|c|c|c|c|c|}
\hline Figure No. & $\begin{array}{l}\text { Color in PRINT } \\
\text { (waive fee) }\end{array}$ & $\begin{array}{l}\text { Color in PRINT } \\
\text { (charge \$500 per) }\end{array}$ & $\begin{array}{l}\text { Color ONLINE ONLY } \\
\text { (no charge) }\end{array}$ & $\begin{array}{l}\text { Black/White ONLINE } \\
\text { and PRINT }\end{array}$ \\
\hline 1 & & & & $X$ \\
\hline 2 & & & & $X$ \\
\hline 3 & & & & \\
\hline 4 & & & & \\
\hline 5 & & $\$ 0$ & & \\
\hline TOTAL: & & & & \\
\hline
\end{tabular}

*If you indicate ANY figures in this column, the contact information below MUST be provided.

Please Complete \& Please Print

\begin{tabular}{|c|c|c|c|}
\hline Component(s) in Article & Charge(s) & Quantity & Estimated Charge(s) (in USD) \\
\hline Color Figure Charge Standard & $\$ 500$ per figure & 0 & $\$ 0$ \\
\hline & & $\$ 0$ & $=$ Total Estimated \\
\hline
\end{tabular}

Name:

Manuscript No.:

Manuscript Title:

Address:

Phone Number:

Fax Number:

Email Address:

Verify your agreement to pay by signing and dating below. Wiley will send an invoice to the email address you've provided:

Date: $7 / 16 / 19$

This article is protected by copyright. All rights reserved. 